\title{
TINJAUAN TEKNIS DAN EKONOMI BEBERAPA BAHAN KOAGULAN UNTUK PENGOLAHAN AIR MINUM DENGAN AIR KALI PROGO SEBAGAI AIR BAKU PADA SPAM REGIONAL YOGYAKARTA, SLEMAN DAN BANTUL
}

\author{
Sindu Nuranto ${ }^{1}$, Syaukat Ali $^{2}$ \\ ${ }^{1,2}$ Prodi Teknik Sipil, Departemen Teknik Sipil, SV, UGM \\ Email: ${ }^{1}$ antonsindu@ gmail.com, ${ }^{2}$ icok@gadjahmada.edu
}

\begin{abstract}
As we understand together that today has begun to decrease the utilization of deep well water and water springs as an alternative source of water in the PDAM, this is due to environmental conditions that have undergone many changes so that our environment has been experiencing a lot of carrying capacity. The selection of deep well water is preferred because the water quality is relatively better than the surface water. This condition causes PDAM to choose surface water such as river water as raw water, such as Progo water which is now used as alternative water for PDAM Kota Yogyakarta, PDAM Sleman and Bantul. Characteristics of surface water are generally poorer than ground water, this is due to more possibilities of contamination with pollutants resulting from human activities such as industry, agriculture and even natural events such as rain. It is physically easy to see that the surface water is generally cloudy compared to groundwater, since surface water generally contains mud and larger suspended particles. To reduce the mud content and suspended particles can be used coagulant material. There are many types of coagulant materials that we know such as alum (Alumunium Sulfate, Sodium Aluminate, Ferro Sulphate, Ferric Sulphate, Ferric Chloride, Lime and others). Technically coagulant capable of decreasing turbidity up to $0 \mathrm{NTU}$ is $\mathrm{Al}_{2}\left(\mathrm{SO}_{4}\right)_{3}$, combination between NaAlO2 and $\mathrm{PAC}$, and combination between $\mathrm{Fe}\left(\mathrm{SO}_{4}\right)$ and PAC. Economically the cheapest coagulant is alum, with the optimum dose not much different but the purchase price is much cheaper than other types of coagulant.
\end{abstract}

Keywords: Coagulant, turbidity, water

\section{PENDAHULUAN}

\section{Permasalahan}

Seperti kita maklumi bersama bahwa dewasa ini sudah mulai berkurang pemanfaatan air sumur dalam maupun mata air sebagai alternatif sumber air di PDAM, hal ini disebabkan kondisi lingkungan yang sudah banyak mengalami perubahan sehingga lingkungan kita sudah banyak mengalami penurunan kemampuan daya dukung. Pemilihan air sumur dalam lebih disukai karena mutu air yang relatif lebih baik dibanding dengan air permukaan. Kondisi tersebut menyebabkan PDAM terpaksa memilih air permukaan seperti air sungai sebagai air baku, seperti air Kali Progo yang saat ini dijadikan alternatif air baku untuk SPAM Regional Kartamantul (Sistim Penyediaan Air Minum Regional Yogyakarta, Sleman dan Bantul. 
Sindu Nuranto, Syaukat Ali, Tinjauan Teknis dan Ekonomi Beberapa Bahan Koagulan untuk

Air Minum di PDAM Tirtamarta Yogyakarta

Karakteristik air permukaan umumnya lebih jelek dibandingkan dengan air tanah, hal ini disebabkan lebih banyak kemungkinan terkontaminasi dengan bahan-bahan pencemar (impurities) hasil aktivitas manusia seperti industri, pertanian bahkan kejadian alam seperti hujan dan sebagainya. Secara fisik mudah dilihat bahwa umumnya air permukaan lebih keruh dibandingkan dengan air tanah, karena air permukaan umumnya mengandung lumpur dan partikel tersuspensi yang lebih besar. Untuk Menurunkan kandungan lumpur dan partikel tersuspensi ini dapat digunakan bahan koagulan. Terdapat banyak jenis bahan koagulan yang kita kenal seperti tawas (Alumunium Sulfat, Natrium Aluminat, Ferro Sulfat, Ferri Sulfat, Ferri Chlorida, Kapur dan lain-lain).

Penelitian ini dimaksudkan untuk mendapatkan jenis koagulan yang secara teknis baik dan secara ekonomi murah, untuk berbagai kondisi air baku yang mutunya sangat fluktuatif sepanjang tahun.

\section{Keaslian Penelitian}

Penelitian tentang bahan koagulan telah banyak dilakukan, namun sejauh pengetahuan penulis belum ada penelitian yang terpadu antara penentuan kadar koagulan untuk berbagai tingkat kekeruhan, pemilihan jenis bahan koagulan, kombinasi penggunaan bahan koagulan, serta tinjauan biaya penggunaan bahan koagulan dalam pengolahan air minum yang menggunakan air baku dari Kali Progo di SPAM Regional Yogyakarta, Sleman dan Bantul.

\section{Faedah yang Dapat Diharapkan}

Secara umum penelitian sangat bermanfaat untuk dapat memberikan gambaran tentang cara pemilihan jenis koagulan, penentuan kadar optimum koagulan, kombinasi penggunaan bahan koagulan serta perkiraan biaya penggunaan bahan koagulan pada proses koagulasi flokulasi yang secara umum digunanakan oleh hampir seluruh PDAM di Indonesia.

\section{Tujuan Penelitian}

Berdasarkan permasalahan di atas, maka penelitian ini bertujuan untuk:

a. Memilih jenis koagulan yang efisien dan aman digunakan dalam proses pengolahan air minum

b. Mencari kadar optimum bahan koagulan untuk berbagai kondisi tingkat kekeruhan air baku

c. Mendapatkan kombinasi bahan koagulan yang hasilnya paling efisia. 
d. Memperkirakan biaya operasional penggunaan bahan koagualan dalam pengolahan air per satuan volume air.

\section{STUDI PUSTAKA}

Koagulasi adalah proses kimia untuk menghilangkan kekeruhan dan bahan penghasil warna yang sebagian besar merupakan partikel koloid seperti ganggang, bakteri, zat organik dan anorganik, dan partikel tanah liat. Sebagian besar padatan koloid dalam air dan air limbah bermuatan negatif. Mekanisme koagulasi kimia melibatkan potensi zeta yang berasal dari kompresi lapisan ganda, netralisasi dengan muatan berlawanan, penghubung antar partikel, dan presipitasi. Destabilisasi partikel koloid dipengaruhi oleh gaya tarik Van der Waals dan gerakan Brown. Koagulasi air dan air limbah umumnya menambahkan aluminium atau garam besi, dengan dan tanpa polimer. Prosesnya kompleks dan melibatkan pembubuhan, hidrolisis, dan polimerisasi; Nilai $\mathrm{pH}$ memainkan peran penting dalam koagulasi kimia tergantung pada alkalinitas. [Lee, C. C. dan Lien, S. D].

Koagulasi yang diartikan sebagai penambahan bahan kimia (koagulan) yang dilakukan dengan pengadukan cepat, diikuti dengan proses berikutnya adalah pengadukan lambat dan didiamkan untuk kesempatan kepada koagulan untuk membentuk inti flok yang terbentuk dari bergabungnya partikel suspensi dan koloid yang ada dalam air. Dengan terpisah dan mengendapnya partikel suspensi dan koloid, akan mengakibatkan air menjadi jernih. [Edzwald, J.K., 1993]

Proses perawatan berbasis kimia seperti kadar koagulan telah menjadi mapan karena mereka efektif, mudah dikendalikan, dan dipahami dengan baik. Secara historis, manfaat praktis ini memiliki beberapa kelemahan karena koagulan berbasis ferri, ferro, dan aluminium tetap relatif murah. Sejumlah besar residu pengolahan air (WTR) yang dihasilkan oleh koagulasi dapat dikembalikan ke titik abstraksi air baku, menghindari biaya pembuangan. Jika pembuangan diperlukan, WTR dianggap lembam, dan pembuangannya hanya menimbulkan biaya sedang. [Keeley, J., Jarvis, P. dan Judd, S. J.].

Faktor yang mempengaruhi proses koagulasi antara lain adalah bahan koagulan, kadar optimum koagulan dan pH optimum seperti diuraikan di bawah ini. [Ma, Z., Qin, J-J., Liou, C-X, Zhang, L., Valiyaveettil, 2012].

(1) Jenis bahan koagulan

Bahan koagulan akan menentukan tingkat pemisahan partikel suspensi dan koloid yang terdapat di dalam air, hal ini disebabkan bahan yang berbeda mempunyai kemampuan 
Air Minum di PDAM Tirtamarta Yogyakarta mengikat partikel yang berbeda. Percobaan koagulasi di laboratorium dengan cara pengadukan dengan menggunakan alat jartest. Sebetulnya proses koagulasi dipengaruhi oleh factor lain yaitu karakteristik air, misalnya kondisi: temperatur, $\mathrm{pH}$, alkalinitas, kekeruhan dan warna.

(2) Penentuan dosis optimum koagulan

Agar didapatkan proses koagulasi yang baik, perlu ditetapkan kadar optimum dari setiap penggunaan bahan koagulan. Kadar optimum akan memberikan hasil yang paling baik, yaitu air dalam kondisi yang paling jernih. Kadar optimum tergantung dari beberapa faktor, antara lain jenis bahan koagulan dan karakteristik air.

(3) $\mathrm{pH}$ optimum

PH optimum adalah nilai $\mathrm{pH}$ air yang dapat memberikan hasil yang paling baik dari proses koagulasi, dengan kadar tertentu pada $\mathrm{pH}$ tersebut hasil koagulasi memberikan air yang paling jernih.

\section{Jenis Koagulan}

Koagulan merupakan bahan kimia yang dibutuhkan untuk membantu proses pengendapan partikel-partikel kecil seperti partikel suspensi dan kolloid yang tidak dapat mengendap secara gravitasi yang menimbulkan kekeruhan dan warna di dalam air. Kekeruhan dan warna dapat dihilangkan melalui penambahan koagulan atau sejenis bahan - bahan kimia antara lain.

Jenis-jenis koagulan:

(1) Alumunium sulfat $\left(\mathrm{Al}_{2}\left(\mathrm{SO}_{4}\right)_{3} \cdot 14 \mathrm{H}_{2} \mathrm{O}\right)$

Alumunium sulfat atau alum atau tawas, adalah bahan koagulan ini banyak digunakan karena sangat efisien untuk menurunkan kadar karbonat. Alum berbentuk kristal atau bubuk putih, larut dalam air, ekonomis, mudah didapat dan mudah disimpan. Penggunaan Alum atau Tawas memiliki keuntungan yaitu harganya yang relatif relatif murah dan sudah dikenal luas oleh masyarakat.

$\mathrm{Al} 2(\mathrm{SO} 4) 3 \rightarrow 2 \mathrm{Al}+3+3 \mathrm{SO} 4-2$

Selain itu akan dihasilkan $\mathrm{H} 2 \mathrm{SO} 4$ yang bersifat asam

$3 \mathrm{SO} 4-2+6 \mathrm{H}+\rightarrow 3 \mathrm{H} 2 \mathrm{SO} 4$

(2) Ferro sulfat $\left(\mathrm{FeSO}_{4}\right)$

Ferro sulfat dikenal juga dengan nama Copper, kombinasi Ferro Sulfat dan kapur sangat efisien digunakan sebagai koagulan dalam proses pengolahan air untuk $\mathrm{pH}$ tinggi. 
(3) Ferri sulfat $\left(\mathrm{Fe}_{2}\left(\mathrm{SO}_{4}\right)_{3}\right)$

Ferri sulfat banyak digunakan untuk memisahkan Fe dan Mn dengan $\mathrm{pH}$ air yang relatif rendah.

(4) Natrium aluminat $\left(\mathrm{NaAlO}_{2}\right)$

Karena harganya relative mahal sehingga jenis bahan koagulan ini (Natrium aluminat) tidak banyak digunakan.

\section{Bahan Koagulan Pendamping}

Bahan koagulan pendamping diperlukan untuk meningkatkan efisiensi penggunaan bahan koagulan..

Jenis koagulan pendamping yang banyak digunakan diantaranya adalah:

(1) Kapur

(2) PAC (Poly Alumunium Chloride)

\section{METODE PENELITIAN}

\section{Lokasi Penelitian}

Rencana penelitian akan dilakukan di Laboratoium Teknik Lingkungan Departemen Teknik Sipil Sekolah Vokasi UGM. Penelitian di laboratorium dimaksudkan untuk mencari data primer, dengan berbagai percobaan misalnya: model jar test untuk proses koagulasi dan flokulasi, model sedimentasi serta berbagai analisis atau pemeriksaan parameter mutu air.

\section{Tahapan Penelitian}

Prinsip dari penelitian ini dapat dibagi menjadi 2 tahap atau jenis penelitian, yaitu:

a. Pemeriksaan di lapangan dan pengambilan sampel air

Pemeriksaan di lapangan dimaksudkan untuk memeriksa parameter mutu air seperti: temperatur, $\mathrm{pH}$, dan DHL. Pemeriksaan di lapangan dilanjutkan dengan pengambilan sampel air untuk keperluan pemeriksaan terhadap parameter lain yang akan dilakukan di laboratorium.

b. Pemodelan di laboratorium disertai pemeriksaan terhadap beberapa parameter mutu air yang diperlukan

Parameter mutu air yang diperiksa di laboratorium meliputi parameter yang tidak dapat diperiksa di lapangan. Selain pemeriksaan parameter mutu air, di laboratorium juga dilakukan pengujian atau pemodelan untuk mencari kadar optimum koagulan dengan menggunakan alat Jartest. 
Sindu Nuranto, Syaukat Ali, Tinjauan Teknis dan Ekonomi Beberapa Bahan Koagulan untuk Pengolahan Air Minum di PDAM Tirtamarta Yogyakarta

\section{HASIL DAN PEMBAHASAN}

Sampel air diambil dari lokasi penelitian yaitu di hulu Jembatan Bantar, Kali Progo, yang merupakan lokasi pengambilan air baku SPAM Kartamantul, untuk dapat menyuplai air bersih ke Wilayah Regional Yogyakarta yang meliputi Kota Yogyakarta, Sleman dan Bantul dengan total debit sekitar $400 \mathrm{lt} / \mathrm{dt}$. Pengambilan sampel air tersebut dilakukan $2 \mathrm{kali}$, yaitu pada musim hujan dan musim kemarau.

Hasil pemeriksanaan mutu air tersebut dapat dilihat pada tabel 1untuk musim kemarau dan tabel 2 untuk musim hujan di bawah ini.

Tabel 1. Sampel Air di Jembatan Bantar pada Musim Kemarau

\begin{tabular}{|c|l|c|c|c|c|}
\hline No & Parameter & Titik_1 & Titik_2 & Titik_3 & Keterangan \\
\hline & Fisik & & & & \\
\hline 2 & Bau & TBB & TBB & TBB & Tidak berbau \\
\hline 3 & Rasa & TBW & TBW & TBW & Tidak berwarna \\
\hline 4 & Kekeruhan & Jernih & Jernih & Jernih & Tidak berasa \\
\hline 5 & Temperatur & 27,5 & 27,5 & 27,5 & ${ }^{\circ} \mathrm{C}$ \\
\hline 6 & TDS & 125 & 121 & 121 & $\mathrm{mg} / \mathrm{l}$ \\
\hline 7 & SS & 0,1 & 0,075 & 0,1 & $\mathrm{mg} / \mathrm{l}$ \\
\hline & Kimia & & & & \\
\hline 1 & pH & 7,1 & 7 & 7,1 & $\mathrm{mhos}$ \\
\hline 2 & DHL & 221 & 214 & 213 & $\mathrm{mg} / \mathrm{l}$ \\
\hline 3 & Fe & 0,01 & 0,01 & 0,01 & $\mathrm{mg} / \mathrm{l}$ \\
\hline 4 & $\mathrm{O}_{2}$ & 6 & 5 & 6 & $\mathrm{mg} / \mathrm{l}$ \\
\hline 5 & $\mathrm{CO}{ }_{2}$ & 2,303 & 2,303 & 2,303 & $\mathrm{mg} / \mathrm{l}$ \\
\hline 6 & $\mathrm{HCO}$ & 73,44 & 57,48 & 51,09 & $\mathrm{mg} / \mathrm{l}$ \\
\hline 7 & Kesadahan & 20,815 & 18,098 & 21,833 & $\mathrm{mg} / \mathrm{l}$ \\
\hline 8 & Ca & 14,36 & 24,63 & 20,52 & $\mathrm{mg} / \mathrm{l}$ \\
\hline 9 & $\mathrm{Mg}$ & 65,08 & 62,79 & 12,31 & $\mathrm{mg} / \mathrm{l}$ \\
\hline 10 & SO4 & 0,5 & 0,5 & 0,5 & $\mathrm{mg} / \mathrm{l}$ \\
\hline 11 & $\mathrm{Cl}$ & 40 & 50 & 7 & $\mathrm{mg} / \mathrm{l}$ \\
\hline 12 & Detergen & 0 & 0 & 0 & \\
\hline
\end{tabular}

Sumber: Data primer

Keterangan: Lokasi Sebelah hulu Jembatan Bantar Sungai Progo

Hari/tgl: Rabu, 17 Mei 2017

Cuaca/musim: kemarau

Tabel. 2 Sampel Air di Jembatan Bantar pada Musim Hujan

\begin{tabular}{|c|l|c|c|c|c|}
\hline No & Parameter & Titik_1 & Titik_2 & Titik_3 & Keterangan \\
\hline & Fisik & & & & \\
\hline 1 & Bau & TBR & TBR & TBR & Tidak berbau \\
\hline 2 & Warna & TBW & TBW & TBW & Tidak berwarna \\
\hline 3 & Rasa & TBR & TBR & TBR & Tidak berasa \\
\hline 4 & Kekeruhan & Agak keruh & Agak keruh & Agak keruh & \\
\hline 5 & Temperatur & 24,2 & 23,5 & 24,1 & ${ }^{\circ} \mathrm{C}$ \\
\hline 6 & TDS & 179 & 185 & 168 & $\mathrm{mg} / \mathrm{l}$ \\
\hline 7 & SS & 1,5 & 1,75 & 1,65 & $\mathrm{mg} / \mathrm{l}$ \\
\hline & Kimia & & & 7,1 & \\
\hline 1 & pH & 7,3 & 7,2 & 341 & $\mathrm{mhos}$ \\
\hline 2 & DHL & 346 & 351 & 0,21 & $\mathrm{mg} / \mathrm{l}$ \\
\hline 3 & Fe & 0,2 & 0,25 & 3 & $\mathrm{mg} / \mathrm{l}$ \\
\hline 4 & $\mathrm{O}_{2}$ & 3 & 3,5 & & \\
\hline
\end{tabular}




\begin{tabular}{|c|l|c|c|c|c|}
\hline 5 & $\mathrm{CO}_{2}$ & 4,55 & 4,43 & 4,61 & $\mathrm{mg} / \mathrm{l}$ \\
\hline 6 & $\mathrm{HCO}_{3}$ & 85,1 & 86,2 & 81,2 & $\mathrm{mg} / \mathrm{l}$ \\
\hline 7 & Kesadahan & 32,3 & 30,1 & 33,7 & $\mathrm{mg} / \mathrm{l}$ \\
\hline 8 & $\mathrm{Ca}$ & 24,9 & 27,3 & 23,8 & $\mathrm{mg} / \mathrm{l}$ \\
\hline 9 & $\mathrm{Mg}$ & 75,7 & 77,3 & 67,5 & $\mathrm{mg} / \mathrm{l}$ \\
\hline 10 & $\mathrm{SO} 4$ & 0,9 & 0,85 & 0,77 & $\mathrm{mg} / \mathrm{l}$ \\
\hline 11 & $\mathrm{Cl}$ & 47 & 50 & 55 & $\mathrm{mg} / \mathrm{l}$ \\
\hline 12 & Detergen & 0 & 0 & 0 & $\mathrm{mg} / \mathrm{l}$ \\
\hline
\end{tabular}

Sumber: Data primer

Keterangan: Lokasi Sebelah hulu Jembatan Bantar Sungai Progo

Hari/tgl: Selasa, 26 September 2017

Cuaca/musim: Hujan

Keterangan: Titik_1 terletak pada 1/3 ruas sungai bagian barat

Titik_2 terletak persis di tengah sungai

Titik_3 terletak pada 1/3 ruas sungai bagian barat

\section{Hasil Percobaan}

Hasil pemeriksaan atau pemodelan untuk mencari dosis optimum koagulan dengan menggunakan alat Jartest dapat dilihat pada tabel-tabel berikut di bawah ini.

Hasil percobaan dengan jenis koagulan $\mathrm{Al}_{2}\left(\mathrm{SO}_{4}\right)_{3}$ dapat dilahat pada Gambar 1 .

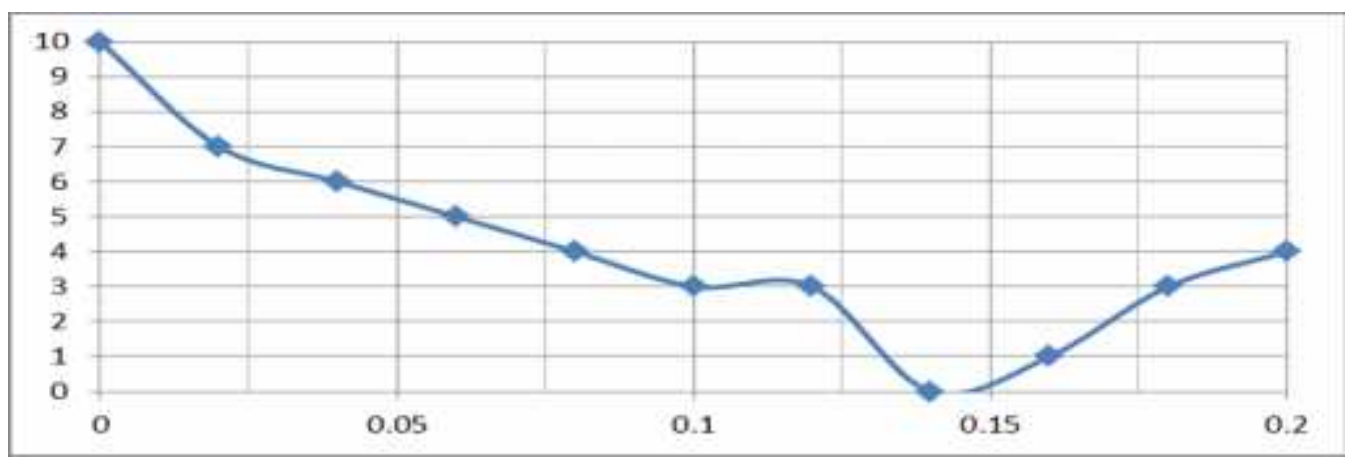

Keterangan: Sumbu X: kadar $\mathrm{Al}_{2}\left(\mathrm{SO}_{4}\right)_{3}$, sumbu Y: kekeruhan Gambar 1. Grafik hubungan antara kadar $\mathbf{A l}_{2}\left(\mathbf{S O}_{4}\right)_{3}$ dengan kekeruhan

Hasil percobaan dengan jenis koagulan $\mathrm{Al}_{2}\left(\mathrm{SO}_{4}\right)_{3}$ dan kapur dapat dilahat pada Gambar 2 berikut ini. 
Air Minum di PDAM Tirtamarta Yogyakarta

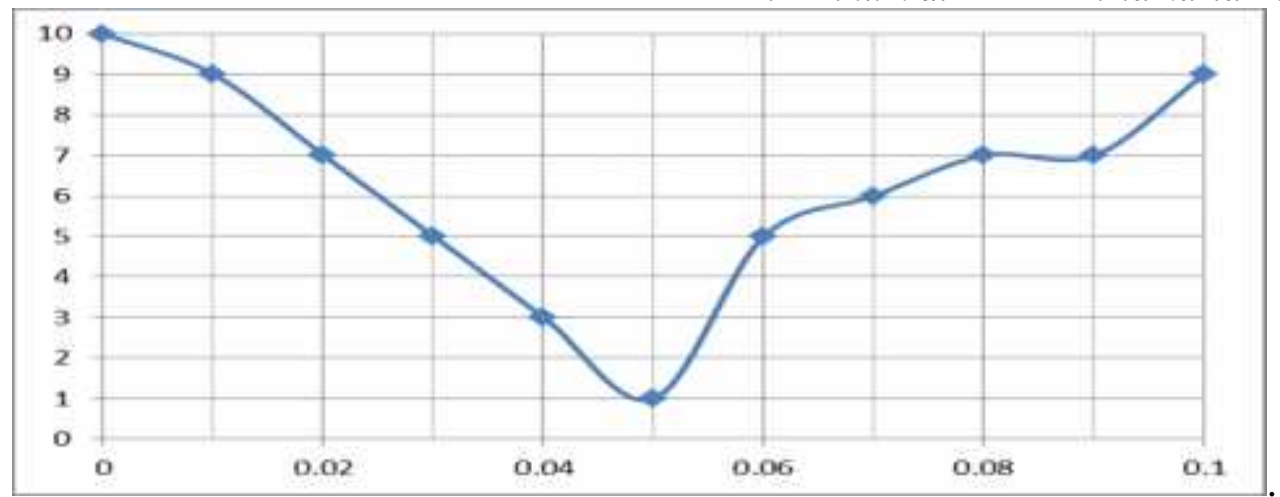

Keterangan: Sumbu X: kadar $\mathrm{Al}_{2}\left(\mathrm{SO}_{4}\right)_{3}$ dan kapur (untuk kapurnya dengan kadar 0,02 mg/l), sumbu Y: kekeruhan

Gambar 2. Grafik hubungan antara kadar $\mathbf{A l}_{2}\left(\mathbf{S O}_{4}\right)_{3}$ dan kapur dengan kekeruhan

Hasil percobaan dengan jenis koagulan $\mathrm{NaAlO}_{2}$ dapat dilahat pada Gambar 3 berikut ini.

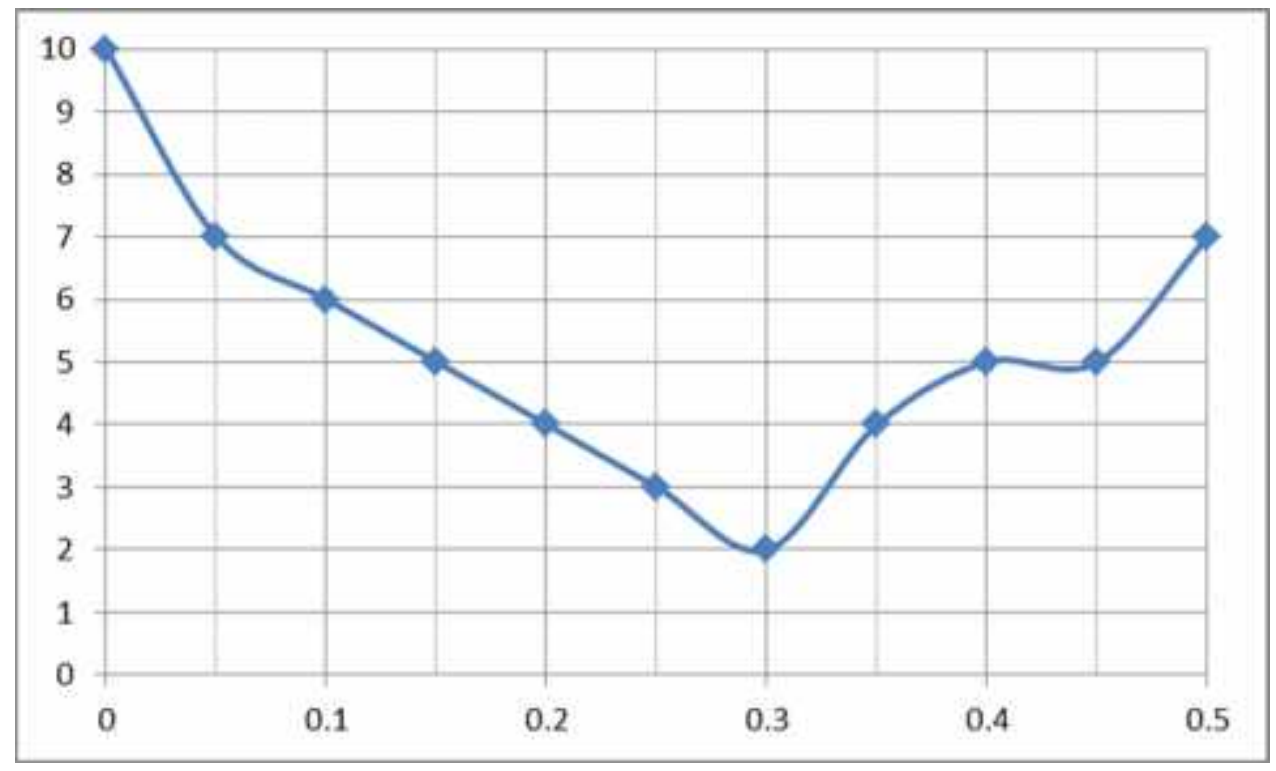

Keterangan: Sumbu X: kadar $\mathrm{NaAlO}_{2}$, sumbu Y: kekeruhan

Gambar 3. Grafik hubungan antara kadar $\mathrm{NaAlO}_{2}$ dengan kekeruhan

Hasil percobaan dengan jenis koagulan $\mathrm{NaAlO}_{2}$ dan PAC dapat dilahat pada Gambar 4 berikut ini. 


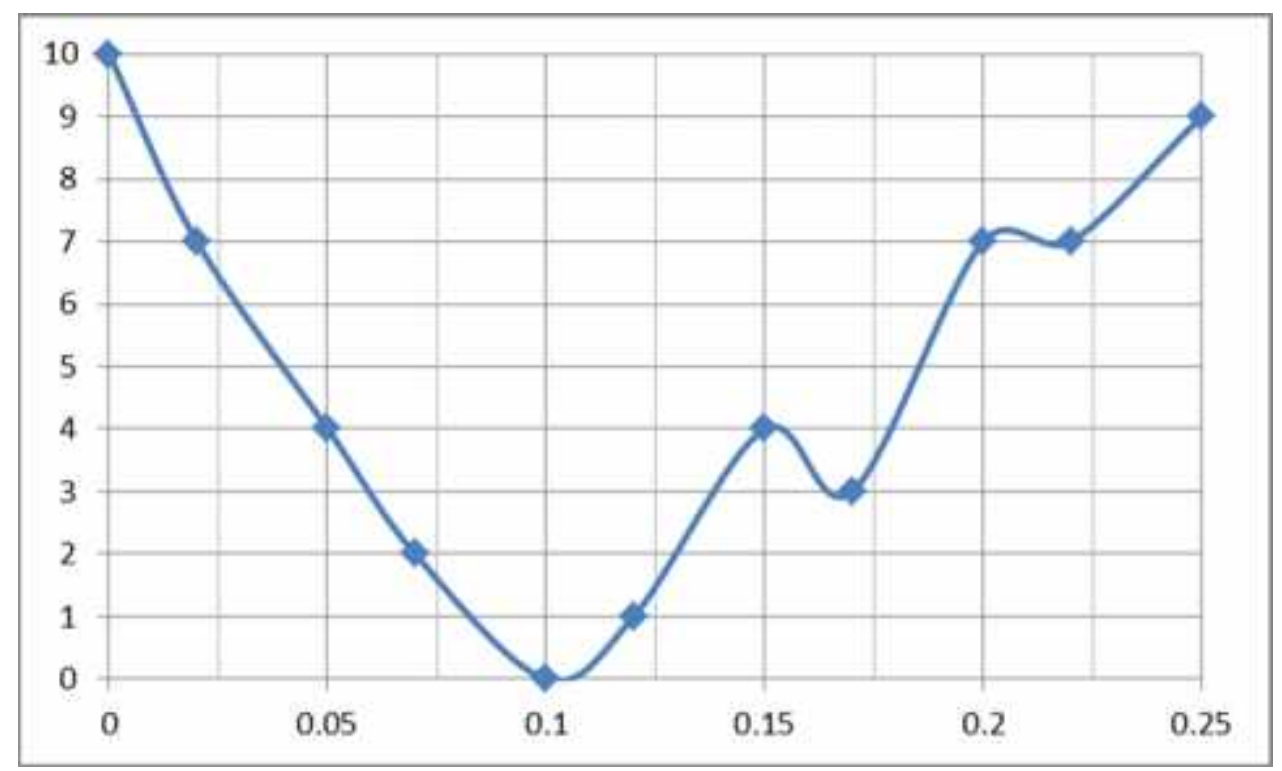

Keterangan: Sumbu X: kadar $\mathrm{NaAlO}_{2}$ dan PAC (untuk kapurnya dengan kadar 0,03 mg/l), sumbu Y: kekeruhan

Gambar 4. Grafik hubungan antara kadar $\mathrm{NaAlO}_{2}$ dan PAC dengan kekeruhan

Hasil percobaan dengan jenis koagulan $\mathrm{Fe}(\mathrm{SO})_{4}$ dapat dilahat pada Gambar 5 berikut ini.

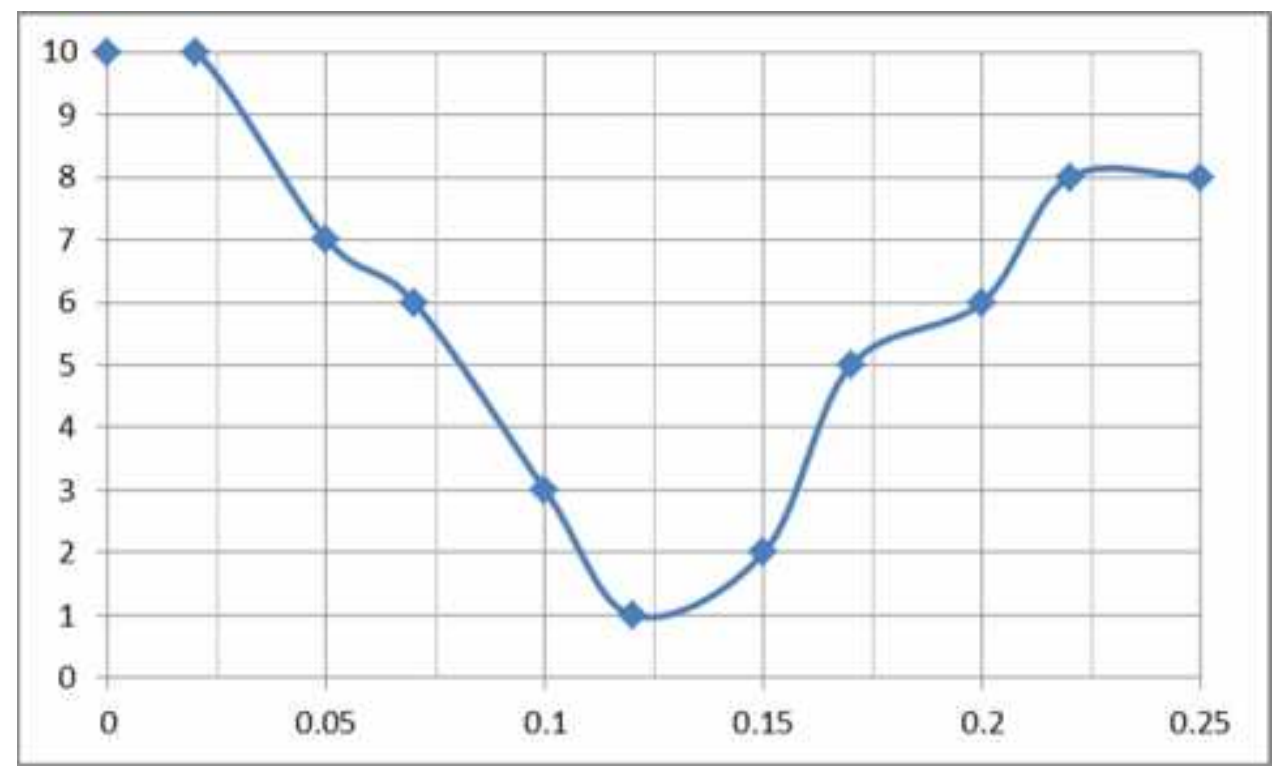

Keterangan: Sumbu X: kadar $\mathrm{Fe}(\mathrm{SO})_{4}$, sumbu Y: kekeruhan

Gambar 5. Grafik hubungan antara kadar $\mathrm{Fe}(\mathrm{SO})_{4}$ dengan kekeruhan 
Air Minum di PDAM Tirtamarta Yogyakarta Hasil percobaan dengan jenis koagulan $\mathrm{Al}_{2}\left(\mathrm{SO}_{4}\right)_{3}$ dan PAC dapat dilahat pada Gambar 6 berikut ini.

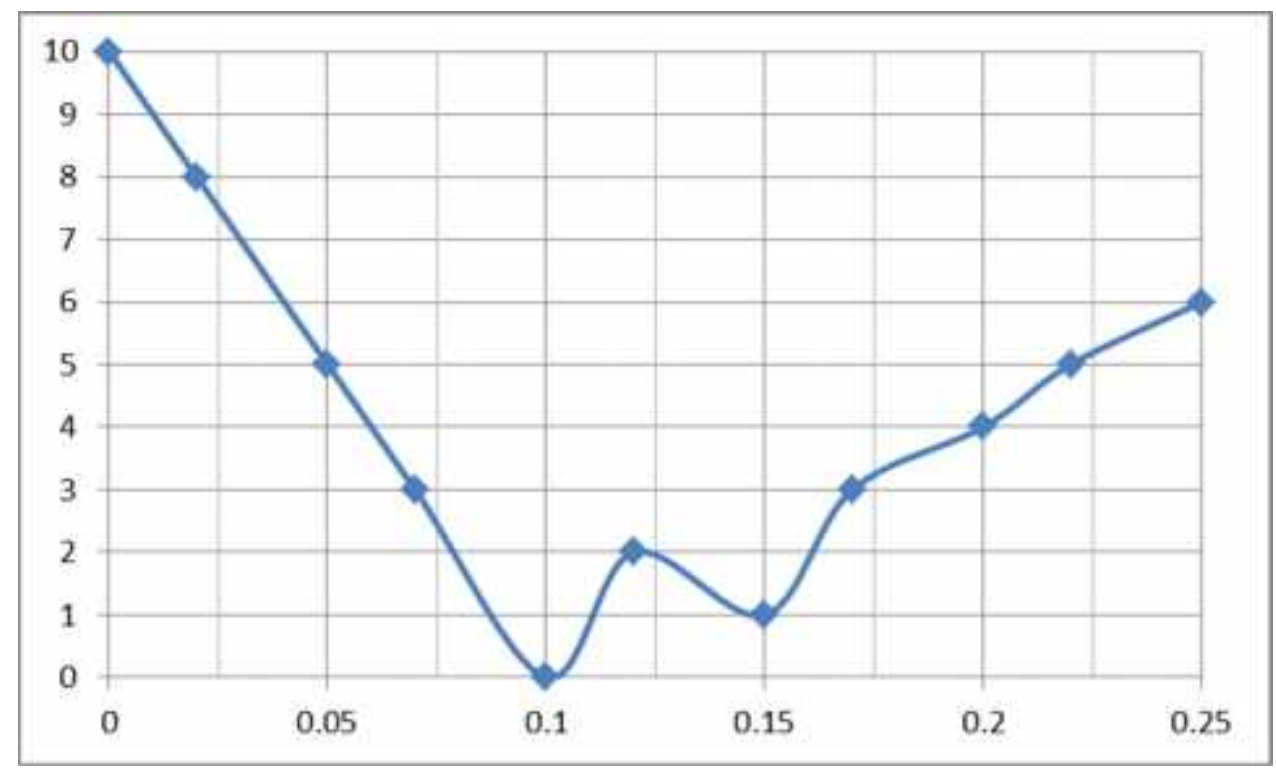

Keterangan: Sumbu X: kadar $\mathrm{Al}_{2}\left(\mathrm{SO}_{4}\right)_{3}$ dan PAC (untuk kapurnya dengan kadar 0,03 mg/l), sumbu Y: kekeruhan

\section{Gambar 6. Grafik hubungan antara kadar $\mathbf{A l}_{2}\left(\mathbf{S O}_{4}\right)_{3}$ dan PAC dengan kekeruhan}

Kadar optimum untuk koagulan:

1. Al2(SO4)3 sebesar $0,14 \mathrm{~g} / 1$ yang dapat menurunkan kekeruhan hingga $0 \mathrm{NTU}$

2. Kombinasi Al2(SO4)3 dan kapur sebesar 0,05 g/l Al2(SO4)3 dan 0,02 g/l kapur yang menurunkan kekeruhan hingga 1 NTU

3. $\mathrm{NaAlO} 2$ sebesar $0,3 \mathrm{~g} / \mathrm{l}$ yang dapat menurunkan kekeruhan hingga $2 \mathrm{NTU}$

4. Kombinasi $\mathrm{NaAlO} 2$ dan PAC sebesar 0,10 g/l NaAlO2 dan 0,03 PAC yang dapat menurunkan kekeruhan hingga 0 NTU

5. $\mathrm{Fe}(\mathrm{SO}) 4$ sebesar $0,12 \mathrm{~g} / \mathrm{l}$ yang dapat menurunkan kekeruhan hingga $1 \mathrm{NTU}$

6. Kombinasi $\mathrm{Fe}(\mathrm{SO} 4)$ dan PAC sebesar 0,10 g/l $\mathrm{Fe}(\mathrm{SO} 4)$ dan 0,01 PAC yang dapat menurunkan kekeruhan hingga 0 NTU.

Aspek ekonomi dari bahan koagulan di atas adalah sebagai berikut:

Harga tawas sekitar Rp. 10.000,00 per kg, sedangkan harga PAC dan Fe(SO4) sekitar Rp. $40.000,00$ per kg. Sehingga dapat dipastikan bahwa secara ekonomi penggunaan tawas (alum) adalah palingmurah dibandingkan dengan penggunaan bahan koagulan lainnya. 


\section{KESIMPULAN DAN SARAN}

\section{Kesimpulan}

Kesimpulan yang dapat disampaikan dari penelitian ini adalah seperti berikut di bawah ini:

1) Secara teknis koagulan yang mampu menurunkan kekeruhan hingga 0 NTU adalah $\mathrm{Al}_{2}\left(\mathrm{SO}_{4}\right)_{3}$, kombinasi antara $\mathrm{NaAlO}_{2}$ dan PAC serta kombinasi $\mathrm{Fe}\left(\mathrm{SO}_{4}\right)$ dan PAC.

2) Secara ekonomi koagulan yang paling murah adalah tawas, dengan dosis optimum yang tidak jauh berbeda tetapi harga belinya jauh lebih murah dibandingkan jenis koagulan lainnya.

\section{Saran}

Saran yang dapat diberikan adalah perlu dilanjutkan dengan penelitian menggunakan kombinasi bahan koagulan yang lebih banyak.

\section{UCAPAN TERIMAKASIH}

Pada kesempatan ini penulis menyampaikan terimakasih kepada Pimpinan Universitas Gadjah Mada dan Pimpinan Sekolah Vokasi UGM, atas kesempatan penelitian yang telah diberikan kepada saya pada tahun 2017 ini.

\section{DAFTAR PUSTAKA}

Edzwald, J.K., 1993, Coagulation in Drinking Water Treatment: Particles, Organics and Coagulants, Depart of Civil Enginerig, University of Massachusett, Amherst, MA OJ 003, USA.

Keeley, J., Jarvis, P. dan Judd, S. J., 2014, Coagulant Recovery from Water Treatment Residuals: A Review of Applicable Technologies, Institut Cranfield Water Science, Universitas Cranfield University, Cranfield, Bedfordshire, Inggris.

Lee, C. C., Lin, S. D., 2007. Handbook of Environmental Engineering Calculations, 2nd edition, McGraw-Hill Companies, New York, Amerika Serikat.

Ma, Z., Qin, J-J., Liou, C-X,Zhang, L., Valiyaveettil, 2012, Effects of Coagulation pH and Mixing Condition on Characterisctics of Flocs in Surface Water Treatment, World Congress on Advances in Civil, Environmental, and Materials Research (ACEM' 12), Soul, Korea, August 26-30, 2012. 